\title{
Potensi Dan Peluang Pengembangan Sentra Produksi Bawang Merah Provinsi Sumatera Utara
}

\author{
Desi Novita1)* \\ Mhd. Asaad2) \\ Teja Rinanda ${ }^{3}$ \\ 1)2) Program Studi Agribisnis, Universitas Islam Sumatera Utara \\ 3) Fakultas Ekonomi, STIE Graha Kirana \\ *e-mail : denovita_02@yahoo.co.id \\ Diterima: September 2019; Disetujui: September 2019; Dipublish: Oktober 2019
}

\begin{abstract}
Abstrak
Bawang merah memiliki peran strategis dalam perekonomian Provinsi Sumatera Utara. Bawang merah merupakan salah satu komoditas utama sebagai penyumbang inflasi. Namun demikian, Provinsi Sumatera Utara masih mengalami defisit bawang merah. Permintaan akan bawang merah akan terus meningkat dari waktu ke waktu. Tujuan penelitian ini adalah untuk melihat perkembangan produksi bawang merah, mengindentifikasi sentra-sentra produksi bawang merah, serta menganalisis peluang investasi usahatani bawang merah di Provinsi Sumatera Utara. Data dalam penelitian ini dianalisis dengan menggunakan metode deskriptif kuantitatif, metode Location Quotient (LQ), serta analisis finansial (RC Rasio, BC Rasio, BEP, dan analisis sensitivitas). Data yang digunakan dalam penelitian ini adalah data primer dengan 35 sampel petani bawang merah dan data sekunder dari 33 kabupaten/kota. Hasil penelitian menunjukkan bahwa produktivitas bawang merah tahun 2018 mencapai 7,83 ton/Ha dengan luas panen sebesar $2.086 \mathrm{Ha}$. Laju pertumbuhan produksi mencapai 5,48\% per tahun dan laju pertumbuhan produktivitas $-1,54 \%$ per tahun. Sentra produksi bawang merah meliputi kabupaten Dairi, Samosir, Toba Samosir, Humbang Hasudutan, Padang Lawas utara, Tapanuli Utara, serta Kabupaten Simalungun. Secara finansial, usahatani bawang merah menguntungkan. Pendapatan usahatani bawang merah Rp 72.116.667 per Ha, RC Rasio sebesar 2,30. BC Rasio 1,30. Harga titik impas dalam usahatani bawang merah mencapai Rp $7.384 / \mathrm{Kg}$.
\end{abstract}

Keywords: Bawang Merah, Produksi, Finansial, Location Quotient (LQ)

\begin{abstract}
Onion has a strategic role in the economy of North Sumatra. Onion is one of the main commodities as a contributor to inflation. However, the Province of North Sumatra is still deficit. Demand for onion will continue to increase from time to time. The purpose of this study was to see the development of onion production, identify onion's production centers, and analyze investment opportunities for red onion farming in North Sumatra Province. The data used in this study are primary data from 35 person of oinion farmer and secondary data. The data in this study were analyzed using quantitative descriptive methods, Location Quotient (LQ) methods, and financial analysis ( $R / C$ ratio, $B / C$ ratio, Break Event Point and sensitivity analysis). The results showed that the productivity 2018 of red onion reached 7.83 tons/ha with a harvest area of 2,086 ha. The center of onion production includes Dairi, Samosir, Toba Samosir, Humbang Hasudutan, North Padang Lawas, North Tapanuli and Simalungun Districts. Financially, red onion farming is financially profitable. Red Onion farming income Rp. 72,116,667 per Ha, RC Ratio of 2.30, BC Ratio 1.30. The price of break-even point in farming red onion reaches $R p .7,384 / \mathrm{Kg}$.
\end{abstract}

Keywords: Red Onion, Production, Financial, Location Quotient (LQ) 


\section{PENDAHULUAN}

Pengembangan ekonomi tidaklah sama antar satu daerah dengan daerah yang lain. Pengembangan ekonomi daerah harus berbasiskan sektor yang menjadi andalan pada setiap daerah. Pengembangan ini bertujuan untuk peningkatan pertumbuhan ekonomi dan kemandirian suatu daerah.

Provinsi Sumatera Utara dikenal sebagai provinsi yang memiliki posisi strategis dalam sektor pertanian. Sektor Pertanian menjadi salah satu penyumbang utama terhadap pembentukan Produk Domestik Regional Bruto (PDRB). Dalam kurun waktu lima tahun terakhir (2013 2017), kontribusi yang disumbangkan sektor pertanian terhadap pembentukan PDRB sekitar 23-25 persen, tertinggi dibandingkan sektor lainnya seperti industri pengolahan maupun sektor perdagangan. Pada tahun 2017, PDRB Provinsi Sumatera Utara Atas Dasar Harga Berlaku (ADHB) mencapai Rp 684,07 trilyun (Badan Pusat Statistika, 2018).

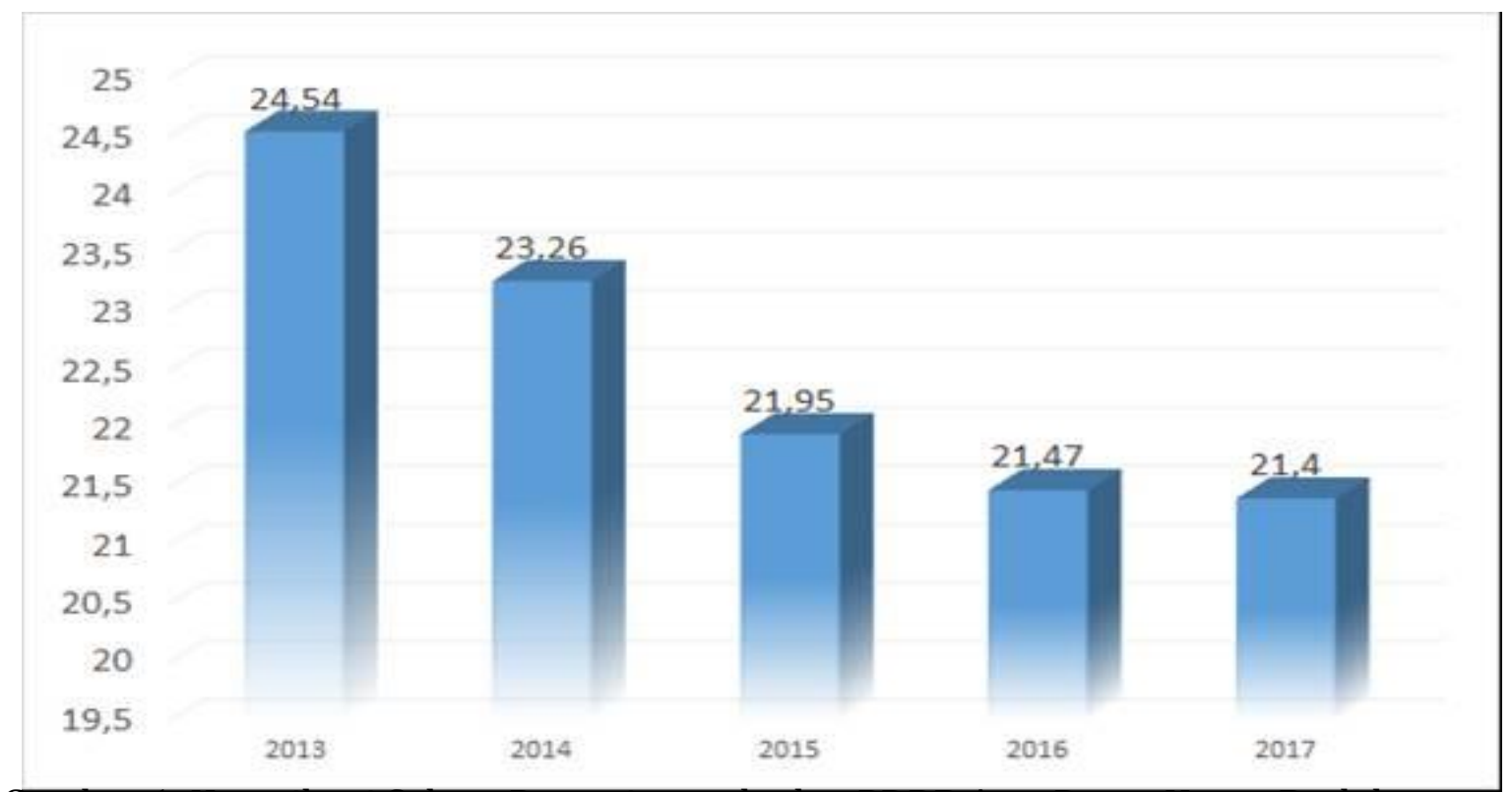

Gambar 1. Kontribusi Sektor Pertanian terhadap PDRB Atas Dasar Harga Berlaku Sumber : Badan Pusat Statistik Provinsi Sumatera Utara (2018)

Salah satu komoditas pertanian yang menjadi perhatian khusus pemerintah Provinsi Sumatera Utara adalah bawang merah. Hal ini disebabkan bawang merah menjadi salah satu sumber pemicu inflasi serta dalam rangka mencapai swasembada bawang merah. Sebagai contoh, inflasi yang terjadi pada bulan April 2019 (BRS BPS, 2019), Provinsi Sumatera Utara mengalami Inflasi sebesar 1,23 persen. Kenaikan harga bawang merah sebesar $17,29 \%$ menjadi salah satu pemicu inflasi setelah kenaikan cabai merah dan bawang putih.

Saat ini, sentra produksi bawang merah umumnya berasal dari pulau jawa sehingga kondisi ini dapat membuat harga cenderung berfluktuasi. Berdasarkan data BPS 
(2019), Provinsi Sumatera Utara merupakan produsen ke delapan terbesar yang menghasilkan bawang merah di Indonesia atau menyumbang $1,09 \%$ terhadap produksi nasional (16.339 Ton).

Prospek pengembangan usaha tani bawang merah saat ini sangat baik. Hal ini ditunjukkan oleh permintaan konsumen yang semakin tinggi seiring dengan semakin meningkatnya jumlah penduduk. Rata-rata konsumsi bawang merah per kapita per tahun menunjukkan sebesar 2,57 Kg (2017). Jumlah penduduk provinsi Sumatera Utara sebanyak 14.262.147 jiwa (BPS, 2018). Sehingga kebutuhan bawang merah mencapai $36.653,7$ ton per tahun. Sementara itu produksi bawang merah pada tahun 2017 sebesar 16.103 ton. Hal ini berarti bahwa Provinsi Sumatera Utara mengalami defisit sebesar 20.550,7 ton. Kondisi ini harus menjadi perhatian bagi pemerintah untuk melakukan percepatan peningkatan produksi bawang merah sehingga swasembada bawang merah dapat tercapai.

Tujuan penelitian ini adalah untuk mengetahui perkembangan produksi bawang merah di Provinsi Sumatera Utara, mengidentifikasi sentra-sentra produksi bawang merah, serta mengetahui potensi investasi khususnya potensi finansial dari usaha tani bawang merah.

\section{METODE PENELITIAN}

Penelitian ini dilakukan di Provinsi Sumatera Utara yang terdiri dari 33 kabupaten/kota. Pemilihan lokasi dilakukan secara sengaja dengan pertimbangkan bahwa provinsi ini merupakan salah satu produsen terbesar di pulau Sumatera dan memungkinkan untuk pengembangan usaha tani bawang merah di masa yang akan datang. Data yang digunakan meliputi data primer dan data sekunder. Data primer diperoleh langsung dari para petani bawang merah pada tahun 2018. Jumlah petani sebanyak 35 orang yang menyebar pada beberapa kabupaten yang ada di Provinsi Sumatera Utara. Sementara itu, data sekunder berupa data runut waktu (Time Series) dan Cross Section dari 33 kabupaten/kota yang diperoleh dari Badan Pusat Statistik, Dinas Tanaman Pangan dan Hortikultura Provinsi Sumatera utara serta dokumen pendukung lainnya yang dikumpulkan melalui studi literatur dan penelusuran data berbasis daring yang relevan dengan topik penelitian.

\section{Tingkat Pertumbuhan Produksi}

Untuk mengetahui perkembangan tingkat pertumbuhan produksi bawang merah dianalisis dengan menggunakan pengukuran dengan menghitung tingkat pertumbuhan produksi per tahun selama kurun waktu 10 tahun terakhir (Tahun 2008 - 2018) dengan rumus (BPS, 2018) :

\footnotetext{
Tingkat pertumbuhan produksi

$=\frac{\text { Produksi tahun } t-\text { produksi tahun } t-1}{\text { produksi tahun } t-1} \times 100 \%-1$
}

\section{Metode Location Quotient (LQ)}

Untuk mengetahui sentra produksi bawang merah dilakukan dengan menggunakan metode Location Quotient (LQ). Menurut Saragih, J.R. (2015), metode LQ digunakan sebagai metode untuk menganalisis konsentrasi dan penyebaran sumber daya wilayah. LQ merupakan suatu indeks yang membandingkan pangsa suatu wilayah dengan pangsa suatu 
wilayah yang lebih agregat. Rumus yang digunakan dalam metode LQ adalah :

$$
\mathrm{LQi}=\frac{\mathrm{Si} / \mathrm{S}}{\mathrm{Ni} / \mathrm{N}}
$$

Keterangan :

$$
\begin{aligned}
& \mathrm{LQi}= \mathrm{LQ} \text { di suatu Kabupaten } \mathrm{i} \\
& \mathrm{Si}= \text { Jumlah Produksi komoditas } \\
& \text { yang diselidiki Kabupaten } \mathrm{i} \\
& \text { (Ton) } \\
& \mathrm{S}= \text { Jumlah Produksi di } \\
& \mathrm{Ni}= \begin{array}{l}
\text { Kabupaten } \mathrm{i} \text { (Ton) } \\
\text { Jumlah Produksi komoditas } \\
\text { yang diselidiki di Provinsi } \\
\text { (Ton) }
\end{array} \\
& \mathrm{N}= \text { Jumlah produksi di } \\
& \text { Provinsi (Ton) }
\end{aligned}
$$

Berdasarkan nilai LQ yang didapat maka :

$$
\begin{aligned}
& \text { LQ > } 1 \text { artinya komoditas yang } \\
& \text { diselidiki memiliki peranan } \\
& \text { yang menonjol daripada } \\
& \text { komoditas lain atau daerah } \\
& \text { tersebut mempunyai } \\
& \text { potensi pada komoditas } \\
& \text { yang diselidiki } \\
& \mathrm{LQ}=1 \text { artinya komoditas yang } \\
& \text { diselidiki hanya mampu } \\
& \text { mencukupi pada daerah } \\
& \text { tertentu } \\
& \mathrm{LQ}<1 \text { artinya daerah tertentu } \\
& \text { tidak memiliki potensi } \\
& \text { pada komoditas yang } \\
& \text { diselidiki }
\end{aligned}
$$

\section{Analisis Pendapatan Usaha Tani}

Untuk mengetahui potensi investasi finansial dalam usaha tani bawang merah maka anlisis pendapatan usaha tani dilakukan dengan menghitung total penerimaan dan total biaya yang dikeluarkan dalam usaha tani bawang merah. Pendapatan merupakan hasil pengurangan total penerimaan (TR) dikurangi dengan total biaya (TC) dalam kegiatan usaha tani bawang merah. Sementara untuk mengetahui kelayakan finansial usaha tani bawang merah dengan menghitung nilai RC Rasio, dan BC Rasio dan Break Event Point (BEP). RC Rasio digunakan untuk melihat apakah sebuah usahatani layak atau tidak. Sementara BC Rasio untuk melihat besaran pendapatan yang diperoleh dengan biaya yang dikeluarkan (Rahim, 2007).

$$
\begin{gathered}
\text { RC Rasio }=\frac{\text { Total Penerimaan (TR) }}{\text { Total Biaya (TC) }} \\
\text { BC Rasio }=\frac{\text { Total Pendapatan }}{\text { Total Biaya (TC) }}
\end{gathered}
$$

Perhitungan RC Rasio dapat menentukan bagaimana keputusan dari sebuah kegiatan usahatani. Kriteria keputusan sebuah usahatani dikatakan merupakan usaha yang menguntungkan atau tidak dapat dilihat dari nilai RC Rasio, dimana jika : $\mathrm{RC}>1$,usahatani yang menguntungkan/ Layak

$\mathrm{RC}<1$, usahatani yang rugi/Tidak layak $\mathrm{RC}=1$, usahatani impas (tidak untung/ tidak rugi)

Kriteria keputusan perhitungan BC Rasio adalah sebagai berikut :

$\mathrm{BC}>1$, usahatani menguntungkan (tambahan manfaat lebih besar dari pada tambahan biaya)

$\mathrm{BC}<1$, usaha tani rugi (tambahan biaya lebih besar dari tambahan manfaat) $\mathrm{BC}=1$, Usaha tani impas (tambahan manfaat sama dengan tambahan biaya)

Perhitungan BEP harga per Kg diperoleh melalui perhitungan sebagai berikut: 


$$
B E P(\text { Harga per } K g)=\frac{\text { Total Biaya }}{\text { Total Produksi }}
$$

\section{Analisis Sensitivitas Usahatani}

Analisis sensitivitas adalah analisis yang dilakukan dengan tujuan untuk mengetahui kondisi penerimaan, biaya, dan pendapatan serta indikator kelayakan keuangan lainnya ketika terjadi perubahan-perubahan dalam proses usahatani. Dalam analisis finansial suatu usaha, perhitungan penerimaan dan pengeluaran didasarkan pada suatu asumsi besaran tertentu. Oleh sebab itu, diperlukan suatu analisis untuk mengetahui kondisi finansial yang mungkin akan terjadi jika terjadi perubahanperubahan di masa yang akan datang.

Analisis sensitivitas dalam penelitian ini digunakan untuk mengetahui sejauh mana usaha budidaya bawang merah mampu mentolerir (sensitif) terjadinya perubahan pada kedua sisi pengeluaran dan penerimaan. Analisis sensitivitas dilakukan dengan menggunakan 6 skenario perubahan, yaitu:

1. Penurunan Produksi $10 \%$

2. Penurunan Produksi $20 \%$

3. Penurunan Harga $15 \%$
4. Penurunan Harga $25 \%$

5. Produksi dan Harga Turun $15 \%$

6. Produksi dan Harga Turun $30 \%$

\section{HASIL DAN PEMBAHASAN \\ Perkembangan Produksi, Luas Panen dan Produktivitas Bawang Merah}

Selama periode tahun 20082018, produksi bawang merah di Provinsi Sumatera Utara cenderung mengalami peningkatan produksi. Pada tahun 2018 ini merupakan produksi tertinggi dalam kurung waktu 11 tahun terakhir yang mencapai 16.339 ton dengan luas areal panen seluas 2.086 Ha. Produksi pada tahun 2018 ini meningkat sebesar $\quad 0,47 \%$ dibandingkan tahun 2017. Peningkatan terbesar terjadi pada tahun 2016 $(33,07 \%)$. Peningkatan produksi yang terjadi dalam kurun waktu lima tahun terakhir ini lebih disebabkan oleh adanya program peningkatan produksi bawang merah yang tertuang dalam Rencana Strategis Kementerian Pertanian Tahun 2015-2019. Dorongan peningkatan produksi bawang merah ini dikarenakan besarnya kontribusi komoditas ini sebagai pemicu inflasi di Provinsi Sumatera Utara.

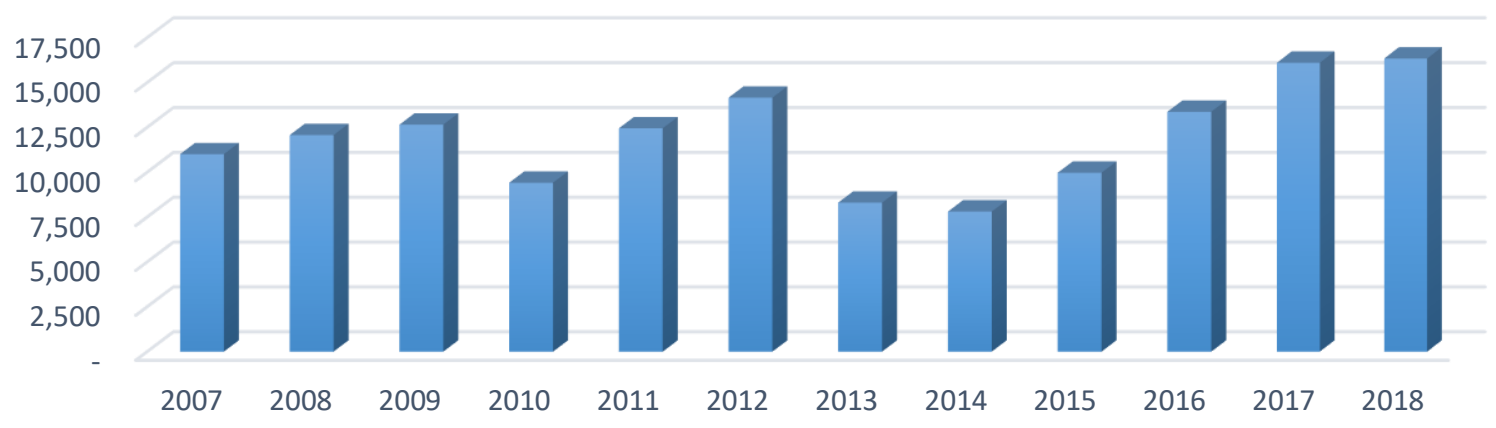

Gambar 2. Perkembangan Produksi Bawang Merah di Provinsi Sumatera Utara 
Tabel 1. Perkembangan Produksi dan Tingkat Pertumbuhan Produksi

\begin{tabular}{ccrr}
\hline Tahun & $\begin{array}{c}\text { Luas Panen } \\
\text { (Ha) }\end{array}$ & $\begin{array}{c}\text { Produksi } \\
\text { (Ton) }\end{array}$ & $\begin{array}{c}\text { Tingkat } \\
\text { Pertumbuhan (\%) }\end{array}$ \\
\hline $2018^{*}$ & 2.086 & 16.339 & 0,47 \\
2017 & 2.090 & 16.103 & 19,46 \\
2016 & 1.538 & 13.368 & 33,07 \\
2015 & 1.238 & 9.971 & 26,67 \\
2014 & 1.003 & 7.810 & $-6,96$ \\
2013 & 1.048 & 8.305 & $-42,33$ \\
2012 & 1.581 & 14.156 & 12,71 \\
2011 & 1.384 & 12.449 & 31,25 \\
2010 & 1.360 & 9.413 & $-26,62$ \\
2009 & 1.379 & 12.655 & 3,84 \\
2008 & 1.238 & 12.071 & 8,69 \\
2007 & 1.204 & 11.005 & $\mathbf{5 , 4 8}$ \\
\hline Rataan/Tahun & $\mathbf{1 . 4 2 9}$ & $\mathbf{1 1 . 9 7 0}$ & \\
\hline
\end{tabular}

Sumber : Badan Pusat Statistik (Diolah)

Berdasarkan tabel 2 diatas, selama kurun waktu 10 tahun terakhir (Tahun 2008 - 2018), produksi bawang merah mengalami peningkatan dengan rata-rata peningkatan per tahun sebesar 5,48\%. Peningkatan produksi ini disebabkan karena adanya peningkatan luas areal panen sebesar
5,74\% per tahun. Sementara itu, jika dilihat dari sisi produktivitas, produktivitas bawang merah di Provinsi Sumatera Utara secara ratarata mengalami penurunan produktivitas sebesar 1,54\% per tahun.

Tabel 2. Perkembangan Produktivitas Bawang Merah (Ton/Ha) Tahun 2007 - 2018

\begin{tabular}{crr} 
Tahun & Produktivitas (Ton/Ha) & Tingkat Pertumbuhan (\%) \\
\hline $2018^{*}$ & 7,83 & 0,66 \\
2017 & 7,71 & 12,36 \\
2016 & 8,69 & 6,92 \\
2015 & 8,05 & 2,43 \\
2014 & 7,79 & $-2,74$ \\
2013 & 7,93 & $-12,49$ \\
2012 & 8,95 & $-1,35$ \\
2011 & 8,99 & 28,82 \\
2010 & 6,92 & $-25,58$ \\
2009 & 9,18 & $-6,88$ \\
2008 & 9,75 & 5,67 \\
2007 & 9,14 & $\mathbf{- 1 , 5 4}$ \\
\hline Rataan/Tahun & $\mathbf{8 , 4 1}$ & \\
\hline
\end{tabular}

Sumber : Badan Pusat Statistik (Diolah) 
Tabel 3. Biaya Investasi Usaha Budidaya Bawang Merah/Ha

\begin{tabular}{clccrr}
\hline No & Uraian Biaya & Volume & Satuan & Harga (Rp) & \multicolumn{1}{c}{ Biaya (Rp) } \\
\hline 1 & Handsprayer & 5 & Unit & 250.000 & 1.250 .000 \\
2 & Cangkul & 10 & Unit & 75.000 & 750.000 \\
3 & Parang & 10 & Unit & 50.000 & 500.000 \\
4 & Gunting Tanaman & 10 & Unit & 50.000 & 500.000 \\
5 & Pompa Air & 1 & Unit & 5.000 .000 & 5.000 .000 \\
6 & Selang Air & 500 & m & 20.000 & 10.000 .000 \\
\hline & & TOTAL & & & $\mathbf{1 8 . 0 0 0 . 0 0 0}$
\end{tabular}

Sumber : Data Primer Diolah

Sementara itu, perhitungan biaya investasi untuk 1 musim tanam per Ha dilakukan dengan melihat nilai penyusutan yang terjadi dengan metode penyusutan garis lurus. Adapun rincian biaya penyusutan yang terjadi seperti yang tergambar pada Tabel 6

Tabel 4. Total Biaya Penyusutan Usaha Budidaya Bawang Merah/Ha/MT

\begin{tabular}{|c|c|c|c|c|c|c|}
\hline No & Komponen & Volume & Satuan & $\begin{array}{c}\text { Biaya } \\
\text { /Komponen } \\
(\mathrm{Rp}) \\
\end{array}$ & $\begin{array}{c}\text { Umur } \\
\text { Ekonomis } \\
\text { (Tahun) }\end{array}$ & $\begin{array}{c}\text { Biaya per } \\
\text { musim } \\
\text { Tanam (Rp) }\end{array}$ \\
\hline 1 & Hand Sprayer & 5 & Unit & 250.000 & 3 & 208.333 \\
\hline 2 & Cangkul & 10 & Unit & 75.000 & 1 & 375.000 \\
\hline 3 & Parang & 10 & Unit & 50.000 & 1 & 250.000 \\
\hline 4 & Gunting & 10 & Unit & 50.000 & 1 & 250.000 \\
\hline 5 & Pompa Air & 1 & Unit & 5.000 .000 & 10 & 250.000 \\
\hline 6 & Selang Air & 500 & $\mathrm{M}$ & 20.000 & 5 & 1.000 .000 \\
\hline
\end{tabular}

Sumber : Data Primer Diolah

\section{a. Biaya Operasional}

Komponen biaya operasional usaha budidaya bawang merah terdiri dari pembelian bahan-bahan yang diperlukan untuk pemeliharaan tanaman seperti pembelian bibit, pestisida, herbisida, dan pupuk. Selain itu juga diperlukan biaya untuk tenaga kerja dalam mengaplikasikan berbagai bahan dan teknologi budidaya untuk penanaman dan pemeliharaan tanaman hingga pemanenan. Komponen penyusunan biaya operasional dalam usaha budidaya bawang merah adalah seperti pada Tabel berikut: 
Tabel 5. Biaya Operasional Usaha Budidaya Bawang Merah/Ha/Musim Tanam

\begin{tabular}{|c|c|c|c|c|c|}
\hline No & Uraian Biaya & Volume & Satuan & $\begin{array}{c}\text { Harga } \\
\text { (Rp) }\end{array}$ & Biaya (Rp) \\
\hline 1 & Bibit & 875 & $\mathrm{~kg}$ & 20.000 & 17.500 .000 \\
\hline \multirow[t]{6}{*}{2} & Tenaga Kerja & & & & \\
\hline & a. Persiapan Lahan & 25 & Rp/Rante & 60.000 & 1.500 .000 \\
\hline & b. Pembuatan Bedengan & 25 & $\mathrm{HOK}$ & 75.000 & 1.825 .000 \\
\hline & c. Penanaman Benih & 15 & $\mathrm{HOK}$ & 50.000 & 750.000 \\
\hline & d.Pemeliharaan & 150 & HOK & 75,000 & 11.250 .000 \\
\hline & e. Panen & 25 & $\mathrm{HOK}$ & 75.000 & 1.850 .000 \\
\hline 3 & Pupuk organik & 40 & Karung & 90.000 & 3.600 .000 \\
\hline \multirow[t]{6}{*}{4} & Pupuk Anorganik & & & & \\
\hline & a. NPK & 250 & $\mathrm{Rp} / \mathrm{kg}$ & 10.000 & 2.500 .000 \\
\hline & b. ZA & 200 & $\mathrm{Rp} / \mathrm{kg}$ & 3.000 & 600.000 \\
\hline & c. Mutiara & 250 & $\mathrm{Rp} / \mathrm{kg}$ & 10.000 & 2.500 .000 \\
\hline & d. Dolomit & 40 & karung & 40.000 & 1.600 .000 \\
\hline & e. Pupuk Pelengkap Cair (PPC) & 25 & Liter & 100.000 & 2.500 .000 \\
\hline \multirow[t]{3}{*}{5} & Fungisida dan Insektisida & & & & \\
\hline & a. Fungisida & 25 & $\mathrm{Kg}$ & 100.000 & 2.500 .000 \\
\hline & b. Insektisida & 25 & Liter & 100.000 & 2.500 .000 \\
\hline & & & TOTAL & & 53.050 .000 \\
\hline
\end{tabular}

Sumber : Data Primer Diolah

\section{Pendapatan Usahatani}

Pendapatan adalah nilai penerimaan setelah dikurangi dengan seluruh biaya yang dikeluarkan dalam usaha budidaya bawang merah. pendapatan dalam satu musim tanam per hektar selama lebih kurang 90 hari dapat dihitung dengan rumus:

$\pi=\mathrm{TR}-\mathrm{TC}$

$$
\begin{aligned}
= & T R-(\text { penyusutan }+ \text { operasional }) \\
= & \operatorname{Rp~127.500.000~}-(\operatorname{Rp~2.333.333+} \\
& \operatorname{Rp~53.050.000)} \\
= & \operatorname{Rp~127.500.000~}-\operatorname{Rp} 55.383 .333 \\
= & \operatorname{Rp~72.116.667,-~} / \mathrm{Ha} / \mathrm{MT}
\end{aligned}
$$

Apabila diasumsikan usaha budidaya bawang merah dalam satu tahun dapat dilakukan 2 musim tanam maka pendapatan/tahun/Ha :

Pendapatan/Tahun/Ha

$=2 \times \operatorname{Rp} 72.116 .667,-=\operatorname{Rp} 144.233 .333,-$

Pendapatan/Bulan/Ha

$=\operatorname{Rp} 12.019 .444,-$

\section{RC Rasio}

Analisis Return Cost (RC) ratio merupakan perbandingan (ratio atau nisbah) antara penerimaan (revenue) dan biaya (Cost). RC Rasio diperhitungkan melalui rumus:

$$
\text { RC Rasio }=\frac{\operatorname{Rp} 127.500 .000}{\operatorname{Rp} 55.383 .333}=2,30
$$

Berdasarkan perhitungan RC Rasio terhadap usaha budidaya bawang merah, terlihat bahwa nilai RC Rasio adalah sebesar 2,30. Dengan kata lain, nilai ini lebih besar dari satu sehingga usaha budidaya bawang merah tersebut merupakan usaha yang menguntungkan untuk dilanjutkan pengusahaannya.

\section{BC Rasio}

BC Rasio merupakan perhitungan yang digunakan untuk 
memperoleh gambaran tentang perbandingan antara manfaat dengan biaya yang diperoleh dalam usaha budidaya bawang merah. Semakin besar angka pembanding dengan kriteria minimal 1, maka kemampuan usaha untuk memberikan manfaat atas setiap rupiah pada usaha budidaya bawang merah akan semakin besar (potensial). Perhitungan BC Rasio pada usahatani adalah sebagai berikut :

$$
\mathrm{BC} \text { Rasio }=\frac{\operatorname{Rp~72.116.667,-}}{\operatorname{Rp~55.383.333,-}}=1,30
$$

Berdasarkan nilai BC Rasio yang diperoleh $(\mathrm{BC}$ rasio $=1,30)$, dapat disimpulkan bahwa usaha budidaya bawang merah merupakan usaha yang menguntungkan. Hal ini berarti juga bahwa usaha budidaya bawang merah ini memberikan tambahan manfaat/benefit yang lebih besar dari pada tambahan biaya yang dikeluarkan oleh petani yakni sebesar 1,30 kali biaya yang dikeluarkan.

\section{Break Event Point (BEP)}

Perhitungan untuk break event point atau titik balik pada usaha budidaya bawang merah yang berkaitan dengan batas minimum harga yang harus tercipta agar seluruh biaya dapat dikembalikan adalah :

BEP untuk harga produksi/ kg

$=\mathrm{Rp} 55.383 .333 / 7.500 \mathrm{~kg}$

$=\mathrm{Rp} 7.384 / \mathrm{Kg}$

Berdasarkan perhitungan break event point untuk harga produksi $/ \mathrm{kg}$, didapat nilai BEP nya adalah Rp 7.384/kg. Nilai ini berarti bahwa untuk mencapai titik pengembalian total biaya per hektar lahan dengan produksi $7.500 \mathrm{~kg} / \mathrm{Ha}$, maka harga / kg yang terbentuk adalah Rp. $7.384 / \mathrm{kg}$.

\section{Analisis Sensitivitas}

Dari hasil analisis sensitivitas yang ada pada tabel di atas dapat diketahui bahwa nilai pendapatan per bulan terendah yang masih didapat oleh petani sebesar $\mathrm{Rp}$ 1.181.944,--. Nilai ini merupakan hasil dari perubahan terjadinya penurunan produksi dan harga jual secara bersamaan sebesar 30\%. Dengan skenario ini, usaha budidaya bawang merah masih menunjukkan nilai yang menguntungkan bagi petani.

\begin{tabular}{|c|c|c|c|c|c|c|c|c|}
\hline \multirow[b]{2}{*}{ Uraian } & \multicolumn{8}{|c|}{ Skenario Analisis Sensitivitas } \\
\hline & Normal & \begin{tabular}{|c|} 
Produksi Turun \\
$10 \%$ \\
\end{tabular} & \begin{tabular}{|c} 
Produksi Turun \\
$20 \%$ \\
\end{tabular} & \begin{tabular}{|c} 
Harga Turun \\
$15 \%$ \\
\end{tabular} & \begin{tabular}{|c} 
Harga Turun \\
$25 \%$ \\
\end{tabular} & $\begin{array}{c}\text { Produksi dan } \\
\text { Harga Turun } \\
15 \% \\
\end{array}$ & \begin{tabular}{|c|} 
Produksi \& \\
Harga Turun \\
$25 \%$ \\
\end{tabular} & $\begin{array}{c}\text { Produksi \& } \\
\text { Harga Turun } \\
30 \%\end{array}$ \\
\hline 1. Produksi (Kg) & 7,500 & 6,750 & 6,000 & 7,500 & 7,500 & 6,375 & 5,625 & 5,250 \\
\hline 2. Harga / Kg & 17,000 & 17,000 & 17,000 & 14,450 & 12,750 & 14,450 & 12,750 & 11,900 \\
\hline 3. Penerimaan & $127,500,000$ & $114,750,000$ & $102,000,000$ & $108,375,000$ & $95,625,000$ & $92,118,750$ & $71,718,750$ & $62,475,000$ \\
\hline 4. Biaya Tetap & $2,333,333$ & $2,333,333$ & $2,333,333$ & $2,333,333$ & $2,333,333$ & $2,333,333$ & $2,333,333$ & $2,333,333$ \\
\hline 5. Biaya Variabel & $53,050,000$ & $53,050,000$ & $53,050,000$ & $53,050,000$ & $53,050,000$ & $53,050,000$ & $53,050,000$ & $53,050,000$ \\
\hline 6. Total Biaya & $55,383,333$ & $55,383,333$ & $55,383,333$ & $55,383,333$ & $55,383,333$ & $55,383,333$ & $55,383,333$ & $55,383,333$ \\
\hline 7. Total Pendapatan/ Musin Tanam & $72,116,667$ & $59,366,667$ & $46,616,667$ & $52,991,667$ & $40,241,667$ & $36,735,417$ & $16,335,417$ & $7,091,667$ \\
\hline 8. Total Pendapatan / Tahun & $144,233,333$ & $118,733,333$ & $93,233,333$ & $105,983,333$ & $80,483,333$ & $73,470,833$ & $32,670,833$ & $14,183,333$ \\
\hline 9. Pendapatan Per Bulan & $12,019,444$ & $9,894,444$ & $7,769,444$ & $8,831,944$ & $6,706,944$ & $6,122,569$ & $2,922,569$ & $1,181,944$ \\
\hline 10. B/CRatio & 1.30 & 1.07 & 0.84 & 0.96 & 0.73 & 0.66 & 0.29 & 0.13 \\
\hline 11. R/CRatio & 2.30 & 2.07 & 1.84 & 1.96 & 1.73 & 1.66 & 1.29 & 1.13 \\
\hline
\end{tabular}

Tabel 6. Analisis Sensitivitas Usaha Budidaya Bawang Merah / Ha 


\section{SIMPULAN}

Hasil penelitian yang telah dilakukan menunjukkan bahwa ratarata pertumbuhan produksi bawang merah di Provinsi Sumatera Utara dalam kurun waktu 10 tahun terakhir sebesar 5,48\% per tahun, akan tetapi dengan laju pertumbuhan produktivitas yang mengalami penurunan rata-rata sebesar $1,54 \%$ per tahun. Berdasarkan hasil analisis LQ, didapat 6 kabupaten yang potensial menjadi sentra untuk mengembangkan produksi bawang merah yakni Dairi, Samosir, Humbang Hasudutan, Padang Lawas Utara, Tapanuli Utara serta Simalungun. Secara finansial, produksi usahatani bawang merah per ha mencapai $7.500 \mathrm{~kg}$ atau senilai $\mathrm{Rp}$ 127.500.000,- dan biaya produksi per ha sebesar Rp 55.383.333,- sehingga menghasilkan pendapatan sebesar Rp 72.116.667,-. Nilai BC, RC rasio, BEP serta analisis sensitivitas menyimpulkan bahwa usahatani bawang merah layak untuk diusahakan.

\section{DAFTAR PUSTAKA}

Badan Pusat Statistik (2018). Sumatera Utara dalam Angka 2017. Badan Pusat Statistik Provinsi Sumatera Utara

Badan Pusat Statistik (2019). Statistik Pertanian Tahun 2018. Diakses melalui http://epublikasi.setjen.pertanian.go.i d/epublikasi/StatistikPertanian/2018 /Statistik\%20Pertanian\%202018/file s/assets/basic-html/page385.html.

Badan Pusat Statistik, Perkembangan Indeks Produksi Triwulanan 2016-2018 Industri Mikro dan Kecil 2016-2018. Diakses
Https://Www.Pertanian.Go.Id/Home /?Show=Page\&Act=View\&Id=61.

Badan Pusat Statistik. Berita Resmi Statistik, Perkembangan Indeks Harga Konsumen/Inflasi No. 23/05/12/Th. Xxii, 2 Mei 2019. BPS Sumatera Utara.

Dinas Tanaman Pangan dan Hortikultura Provinsi Sumatera Utara (2019).

H. Susanti, K. Budiraharjo, Dan M. Handayani. Analisis Pengaruh FaktorFaktor Produksi Terhadap Produksi Usahatani Bawang Merah Di Kecamatan Wanasari Kabupaten Brebes. Agrisocionomics Jurnal Sosial Ekonomi Pertanian Issn 2580-0566 Http://Ejournal2.Undip.Ac.Id/Index.P hp/Agrisocionomics 2(1): 23-30, Mei 2018.

Novita, Desi, and Hartono Gultom. "Penentuan Sektor Unggulan Dalam Perekonomian Wilayah Kabupaten Langkat Pendekatan Sektor Pembentuk PDRB." Agrium: Jurnal Ilmu Pertanian 21, no. 1 (2017): 4954.

Peraturan Menteri Pertanian Republik Indonesia Nomor 19/Permentan/Hk.140/4/2015

Tentang Rencana Strategis Kementerian Pertanian Tahun 20152019

Rahim, Abd dan Hastuti, DRD, 2007. Pengantar, Teori, dan Kasus Ekonomika Pertanian. Penebar Swadaya, 2007.

Rahma, A. Dan R. Sipayung. 2013. Pertumbuhan Dan Produksi Bawang Merah Dengan Pemberian Pupuk Kandang Ayam Dan Em. Jurnal Agroekoteknologi. 1(4): 952-963.

Saragih, J.R., 2015. Perencanaan Wilayah dan Pengembangan Ekonomi Lokal Berbasil Pertanian. Penerbit Pustaka Pelajar Yogyakarta, 2015.

Tarigan, Robinson (2006). Ekonomi Regional : Teori dan Aplikasi. Penerbit Bumi Aksara, Jakarta. 
Lampiran 1.

Tabel 7. Nilai LQ berdasarkan Kabupaten di Provinsi Sumatera Utara

\begin{tabular}{|c|c|c|c|c|c|}
\hline \multirow{2}{*}{ No } & \multirow{2}{*}{ Kabupaten } & \multicolumn{2}{|c|}{ Nilai LQ } & \multirow{2}{*}{ Rataan } & \multirow{2}{*}{$\begin{array}{c}\text { Basis/Non } \\
\text { Basis }\end{array}$} \\
\hline & & 2017 & 2018 & & \\
\hline 1 & Nias & 0,00 & 0,00 & 0,00 & Non Basis \\
\hline 2 & Madina & 0,02 & 0,48 & 0,25 & Non Basis \\
\hline 3 & Tapanuli Selatan & 0,24 & 0,22 & 0,23 & Non Basis \\
\hline 4 & Tapanuli Tengah & 0,00 & 0,00 & 0,00 & Non Basis \\
\hline 5 & Tapanuli Utara & 1,24 & 1,71 & 1,47 & Basis \\
\hline 6 & Toba Samosir & 2,42 & 5,30 & 3,86 & Basis \\
\hline 7 & Labuhan Batu & 0,00 & 0,00 & 0,00 & Non Basis \\
\hline 8 & Asahan & 0,25 & 0,21 & 0,23 & Non Basis \\
\hline 9 & Simalungun & 1,15 & 1,38 & 1,27 & Basis \\
\hline 10 & Dairi & 7,73 & 4,27 & 6,00 & Basis \\
\hline 11 & Karo & 0,73 & 0,52 & 0,63 & Non Basis \\
\hline 12 & Deli Serdang & 0,49 & 0,83 & 0,66 & Non Basis \\
\hline 13 & Langkat & 0,02 & 0,00 & 0,01 & Non Basis \\
\hline 14 & Nias Selatan & 0,00 & 0,00 & 0,00 & Non Basis \\
\hline 15 & Humbang Hasundutan & 3,38 & 3,34 & 3,36 & Basis \\
\hline 16 & Pakpak Bharat & 0,00 & 1,62 & 0,81 & Non Basis \\
\hline 17 & Samosir & 6,00 & 4,91 & 5,45 & Basis \\
\hline 18 & Serdang Bedagai & 0,14 & 0,11 & 0,13 & Non Basis \\
\hline 19 & Batu Bara & 0,07 & 0,07 & 0,07 & Non Basis \\
\hline 20 & Padang Lawas Utara & 2,43 & 3,39 & 2,91 & Basis \\
\hline 21 & Padang Lawas & 0,00 & 0,37 & 0,19 & Non Basis \\
\hline 22 & Labuhan Batu Selatan & 0,00 & 0,00 & 0,00 & Non Basis \\
\hline 23 & Labuhan Batu Utara & 0,00 & 0,46 & 0,23 & Non Basis \\
\hline 24 & Nias Utara & 0,00 & 0,00 & 0,00 & Non Basis \\
\hline 25 & Nias Barat & 0,00 & 0,00 & 0,00 & Non Basis \\
\hline 26 & Sibolga & 0,00 & 0,00 & 0,00 & Non Basis \\
\hline 27 & Tanjung Balai & 0,00 & 0,22 & 0,11 & Non Basis \\
\hline 28 & Pematang Siantar & 0,00 & 0,00 & 0,00 & Non Basis \\
\hline 29 & Tebing Tinggi & 0,12 & 0,43 & 0,27 & Non Basis \\
\hline 30 & Medan & 0,08 & 0,39 & 0,24 & Non Basis \\
\hline 31 & Binjai & 0,00 & 0,00 & 0,00 & Non Basis \\
\hline 32 & Padang Sidempuan & 0,54 & 0,05 & 0,29 & Non Basis \\
\hline 33 & Gunung Sitoli & 1,05 & 0,67 & 0,86 & Non Basis \\
\hline
\end{tabular}

Sumber : Data Sekunder dari berbagai sumber (Diolah) 